\title{
INTEGRAL GENERALIZED MEANS
}

\author{
GHEORGHE TOADER
}

Abstract. Generalizing the integral representation of the arithmetic-geometric mean, some authors characterized more means by integrals. In this paper we extend a modified method used by Y.-H. Kim to construct generalized means.

Mathematics subject classification (2000): 26E60.

Key words and phrases: generalized mean, arithmetic-geometric mean, integral mean.

\section{REFERENCES}

[1] J. ACZÉL, L. LOSONCZI, Z. PÁLES, The behaviour of comprehensive classes of means under equal increments of their variables, Gen. Ineq. 5, Oberwolfach 1986, Internat. Sem. Numer. Math. 80 (1987), 459-461.

[2] P. S. Bullen, D. S. Mitrinović, P. M. Vasić, Means and Their Inequalities, Reidel, Dordecht, 1988.

[3] D. M. E. Foster, G. M. PhILLIPS, A generalization of the archimedean double sequence, J. Math. Anal. Appl. 101 (1984), 575-581.

[4] H. HARUKI, New characterizations of the arithmetic-geometric mean of Gauss and other well-known mean values, Publ. Math. Debrecen 38 (1991), 323-332.

[5] H. HARUKI, T. M. RASSIAS, New characterizations of some mean-values, J. Math. Anal. Appl. 202 (1996), 333-348.

[6] H. HARUKI, T. M. Rassias, A new analogue of Gauss' functional equation, Internat. J. Math. \& Math. Sci. 18 (1995), 749-756.

[7] Y.-H. KIM, On some further extensions of the characterizations of mean values by H. Haruki and Th. M. Rassias, J. Math. Anal. Appl. 235 (1999), 2, 598-607.

[8] G. TOADER, Some remarks on means, Anal. Numèr. Théor. Approx. 29 (1991), 1-2, 97-109.

[9] G. TOADER, Some mean values related to the arithmetic-geometric mean, J. Math. Anal. Appl. 218 (1998), 358-368.

[10] G. TOADER, T. M. Rassias, New properties of some mean values, J. Math. Anal. Appl. 232 (1999), 376-383.

[11] SILVIA TOADER, Derivatives of generalized means Math. Ineq. Appl. 5 (2002), 3 (to appear).

[12] S. TOAdER, T. M. RASSiAS, G. TOAdER, A Gauss type functional equation, Internat. J. Math. Math. Sc. 25 (2001), 9, 565-569.

[13] J.-S. Ume, Y.-H. KIM, Some mean values related to the quasi-arithmetic mean, J. Math. Anal. Appl. 252 (2000), 1, 167-176. 